\title{
Numerical Calculation of Wall-to-Bed Heat- Transfer Coefficients in Gas-Fluidized Beds
}

\author{
J. A. M. Kuipers, W. Prins, and W. P. M. van Swaaij \\ Department of Chemical Engineering, Twente University of Technology, 7500 AE Enschede, The Netherlands
}

\begin{abstract}
A computer model for a hot gas-fluidized bed has been developed. The theoretical description is based on a two-fluid model (TFM) approach in which both phases are considered to be continuous and fully interpenetrating. Local wall-to-bed heattransfer coefficients have been calculated by the simultaneous solution of the TFM conservation of mass, momentum and thermal energy equations. Preliminary calculations suggest that the experimentally observed large wall-to-bed heat-transfer coefficients, frequently reported in literature, can be computed from the present hydrodynamic model with no turbulence. This implies that there is no need to explain these high transfer rates by additional heat transport mechanisms (by turbulence).

The calculations clearly show the enhancement of the wall-to-bed heat-transfer process due to the bubble-induced bed-material refreshment along the heated wall. By providing detailed information on the local behavior of the wall-to-bed heattransfer coefficients, the model distinguishes itself advantageously from previous theoretical models. Due to the vigorous solids circulation in the bubble wake, the local wall-to-bed heat-transfer coefficient is relatively large in the wake of the bubbles rising along a heated wall.
\end{abstract}

\section{Introduction}

Because of their favorable heat-transfer properties fluidized beds find a widespread application in highly thermal processes. Many of these applications involve the transfer of heat between the bed and immersed surfaces but yet it is very difficult to predict values for the corresponding heat-transfer coefficients with confidence. Many empirical correlations for bed-wall and bed-immersed tube heat-transfer coefficients have been proposed in the literature but the use of these expressions is limited to the experimental conditions on which they are based: predicted heat-transfer coefficients may differ by almost two orders of magnitude from the actual coefficients in some cases (Gelperin and Einstein, 1971). Thus, the designer of fluidizedbed heat-transfer systems should cautiously use such correlations in estimating heat-transfer coefficients. From a scientific point of view, these empirical correlations are less attractive because they generally do not contribute to the understanding of the fundamental transport mechanisms.

Therefore, several investigators have developed mechanistic models for the prediction of heat-transfer coefficients, the most

Correspondence concerning this article should be addressed to J. A. M. Kuipers. useful type being based upon transient conduction between the particles and the surface. These type of mechanistic models can roughly be divided into single particle models and emulsion phase models.

\section{Single-particle models}

In single-particle models the fluidized bed is considered as a heterogeneous system consisting of a continuous phase (that is, the fluidizing medium) and a discrete phase (that is, the solid particles). The heat-transfer process for single particles during their residence at the heat exchanging surface is described in terms of two separate transient heat conduction equations.

This model type was developed in its simplest form by Botterill and Williams (1963). They considered an isolated particle, surrounded by a stagnant fluid (that is, a gas or a liquid), and in contact with a heat-transfer surface for a certain time, during which heat was transferred to it. An explicit finite difference technique was used to solve the transient heat conduction equations. Botterill and Williams (1963) compared their model pre- 
dictions with experimental data obtained from a mechanically stirred fluidized-bed heat exchanger under closely controlled particle residence time conditions. Their theoretical predictions deviated considerably from the experimental data and in order to remove this shortcoming of the model, they introduce a gas film or gas gap with a thickness of approximately $0.1 d_{p}$ between the particle and the surface. The modified model showed then good agreement between the predicted and experimental data for short particle residence times. However, the assumption of such a gas gap does not correspond to the physical reality and has been criticized, among others, by Schlünder (1971). Besides, the single particle model of Botterill and Williams (1963) fails if the heat from the transfer surface penetrates beyond the first layer of particles which is the case at relatively long particle residence times.

This failure of the single particle model has been recognized by Botterill and Butt (1968) and Gabor (1970) who proposed respectively a model with two spherical particles normal to the heat-transfer surface and a model with a string of spherical particles of infinite length normal to the heat-transfer surface. In both studies a finite difference technique was used to solve the transient heat conduction equations on the multiple particle domain. Satisfactory agreement between the theoretical predictions and the experimental data was obtained in both studies under closely controlled particle residence time conditions. Gabor (1970) also proposed, as an alternative to his "string of spheres model," a computationally less complicated model based on transient heat conduction through a series of alternating gas and solid slabs.

\section{Emulsion-phase models}

The emulsion-phase or packet-renewal models are in some respects similar to the continuum approach adopted in the present study and use the analogy between a fluidized bed and a liquid. Here the emulsion phase is considered to be the continuous phase and the bubbles to be the discrete phase. Mickley and Fairbanks (1955) proposed such a packet renewal model postulating that heat is transferred by "packets" of emulsion phase which are periodically replaced from the heat-transfer surface by bubbles. According to the packet renewal model the local instantaneous heat-transfer coefficient $h_{i}$ is given by:

$$
h_{i}=\sqrt{\frac{\kappa_{m}\left(\rho C_{p}\right)_{m}}{\pi t_{p}}}
$$

where, $t_{p}$ is the time for which the packet was in contact with the heat-transfer surface. In terms of the packet renewal models, the thermophysical properties within the packet are considered to be uniform and are usually evaluated at bed conditions corresponding to incipient fluidization. However, due to the bed voidage variation near the constraining heat-transfer surface, the thermophysical properties of the packet close to the surface will differ from those in the bulk of the emulsion phase. In fluidized beds the principal voidage variation occurs within one particle diameter from the surface (Korolev et al., 1971) which implies that the thickness of the surface layer of altered thermophysical properties is approximately one particle diameter. Most probably, the effect of this surface layer or packet heterogeneity is negligible for packets with a heat penetration depth $\delta \gg d_{p}$, thus for packets with relatively large residence times. However, at relatively short packet residence times the effect of this surface layer becomes increasingly important and the simple emulsion phase model fails. Therefore, this model type has been refined by several workers (Baskakov, 1969; Kubie and Broughton, 1975) to extend its validity to relatively short packet residence times.

Baskakov (1969) introduced the concept of a time-independent contact resistance to account for the spatial voidage variation near the surface. Kubie and Broughton (1975) modified the simple packet renewal theory to allow for property variations near the heat-transfer surface. They used simple geometrical considerations to model the spatial voidage variation normal to the heat-transfer surface and subsequently used the resulting expression for the voidage profile to describe the corresponding property variations. Despite their simplicity, the use of these (refined) emulsion phase models has limited applicability, because they all require information regarding the actual packet residence times that exist in fluidized beds. Unfortunately, such hydrodynamic parameters cannot easily be obtained by experimental methods. Ozkaynak and Chen (1980) reported measurements of the particle residence time distribution on a vertical tube immersed in a fluidized bed, obtained by a fast response capacitance probe mounted in the surface of the tube. They obtained good agreement between experimentally determined heat-transfer coefficients and the predictions according to the packet renewal model provided that the measured root-square-mean packet residence times were used in the model. From a scientific point of view, their approach is less satisfactory because it requires the use of a a posteriori empirical constant.

The two-fluid model (TFM) approach, adopted in the present study, has the advantage over previous models reported in literature that it does not require the input of empirical parameters such as the average particle or packet residence time; the bed hydrodynamics evolves naturally from the solution of the TFM conservation of mass and momentum equations. However, to account for microscale (that is, on the scale of a representative unit cell of particles and interstitial fluidum) momentum and heat transfer between the phases, the present mesoscale model incorporates two empirical expressions for respectively the interphase momentum transfer coefficient and the interphase heat-transfer coefficient. For the further development of the mesoscale model, mechanistic models should be developed which describe momentum and heat transfer on microscale.

Previous work has shown that the hydrodynamic model can predict bubble sizes (Kuipers et al., 1991) and void distributions (Kuipers et al., 1992b) in a cold-flow two-dimensional gasfluidized bed satisfactorily without the use of any fitted parameters. These results provide an indirect experimental validation of the empirical expression for the interphase momentum transfer coefficient. In the present study, the wider applicability of this model to predict wall-to-bed heat-transfer coefficients in gas-fluidized beds will be explored. It must be emphasized, that the present model should be considered as a learning model and not as the most efficient way to predict, for example, average wall-to-bed heat-transfer coefficients.

\section{Theoretical Model}

The present heat-transfer model is based on a TFM approach in which both phases are considered to be continuous and fully 
Table 1. Two-Fluid Model Conservation of Mass, Momentum and Thermal Energy Equations in Vector Form

\section{Continuity Equations}

Fluid phase:

$$
\frac{\partial\left(\epsilon \rho_{f}\right)}{\partial t}+\left(\nabla \cdot \epsilon \rho_{f} \bar{u}\right)=0
$$

Solid phase:

$$
\frac{\partial\left[(1-\epsilon) \rho_{s}\right]}{\partial t}+\left[\nabla \cdot(1-\epsilon) \rho_{s} \bar{v}\right]=0
$$

Momentum Equations

Fluid phase:

$$
\frac{\partial\left(\epsilon \rho_{f} \bar{u}\right)}{\partial t}+\left(\nabla \cdot \epsilon \rho_{f} \bar{u} \bar{u}\right)=-\epsilon \nabla p-\beta(\bar{u}-\bar{v})+\epsilon \rho_{f} \bar{g}
$$

Solid phase:

$$
\begin{aligned}
\frac{\partial\left[(1-\epsilon) \rho_{s} \bar{v}\right]}{\partial t}+\left[\nabla \cdot(1-\epsilon) \rho_{s} \bar{v} \bar{v}\right] & =-(1-\epsilon) \nabla p \\
+ & \beta(\bar{u}-\bar{v})-G(\epsilon) \nabla \epsilon+(1-\epsilon) \rho_{s} \bar{g}
\end{aligned}
$$

Thermal Energy Equations

Fluid phase:

$$
\begin{aligned}
\frac{\partial\left(\epsilon \rho_{f} I_{f}\right)}{\partial t}+\left(\nabla \cdot \epsilon \rho_{f} I_{f} \bar{u}\right)=-p\left\{\frac{\partial \epsilon}{\partial t}\right. & +(\nabla \cdot \epsilon \bar{u})\} \\
& +\left(\nabla \cdot \epsilon \kappa_{f} \nabla T_{f}\right)-\alpha\left(T_{f}-T_{s}\right)
\end{aligned}
$$

Solid phase:

$$
\begin{aligned}
\frac{\partial\left[(1-\epsilon) \rho_{s} I_{s}\right]}{\partial t}+\left[\nabla \cdot(1-\epsilon) \rho_{s} I_{s} \bar{v}\right] & =-p\left\{\frac{\partial(1-\epsilon)}{\partial t}+[\nabla \cdot(1-\epsilon) \bar{v}]\right\} \\
+ & {\left[\nabla \cdot(1-\epsilon) \kappa_{s} \nabla T_{s}\right]+\alpha\left(T_{f}-T_{s}\right) }
\end{aligned}
$$

interpenetrating. Table 1 shows the TFM mass, momentum and thermal energy conservations equations for both phases in vector form. As evident from these equations, the present hydrodynamic model does not contain turbulence terms. In our point of view (which is supported by experimental evidence) the macroscopic (that is, on the scale of the size of bubbles) turbulent transport in dense gas-solid systems such as gasfluidized beds does not constitute a dominant transport mechanism. This has been demonstrated in a qualitative sense (Rowe, 1971) by injecting a tracer gas $\left(\mathrm{NO}_{2}\right)$ in a bubbling two-dimensional gas-fluidized bed. In these experiments no appreciable lateral mixing of the injected $\mathrm{NO}_{2}$ could be observed which implies the absence of turbulence in the gas phase and therefore the absence of turbulence in the solid phase since the motion of solid particles in gas-fluidized systems is driven by the gas motion and not vice versa. However, for very dilute systems turbulent transport becomes more important due to the low concentration of particles which dampen the gas phase turbulence.

In addition it should be noticed that the viscous stresses in both momentum equations have been omitted. This approximation is valid due to the fact that the interphase momentum transfer coefficient $\beta$ is the dominant term in the momentum equations. Our computational experience has revealed that the sensitivity of the models predictions (that is, calculated bubble parameters such as shape and size) with respect to the value of the solid phase viscosity is low.

As discussed in Kuipers et al. (1992a), the solution of the balance equations, listed in Table 1 , involves the specification of the so-called "primary" or basic variables and subsequent specification of the constitutive equations which define the remaining variables in terms of the basic variables. Here, the porosity $\epsilon$, the pressure $p$, the fluid phase temperature $T_{f}$, the solid phase temperature $T_{s}$, the fluid phase velocity vector $\bar{u}$ and the solid phase velocity vector $\bar{v}$ constitute the basic variables. The additional constitutive equations provide the necessary empirical information. The major empirical input in the hydrodynamic model is the interphase momentum transfer coefficient $\beta$ which was obtained from well-established literature correlations (Kuipers et al., 1992a). Only the constitutive equations associated with the thermal energy equations will be considered here.

\section{Internal energies $I_{f}$ and $I_{s}$}

The internal energies of both phases are related to their respective temperatures by the caloric equations of state:

$$
d I_{f}=C_{p, f} d T_{f}
$$

and

$$
d I_{s}=C_{p, s} d T_{s}
$$

where $C_{p, f}$ and $C_{p, s}$ represent respectively the fluid phase and solid phase heat capacity. In the present study, both are assumed to be independent of the temperature.

\section{Interphase heat-transfer coefficient $\alpha$}

The interphase heat-transfer term in equations (T1-5) and (T1-6) is written in standard form as the product of a transfer coefficient $\alpha$ and a driving force $\left(T_{f}-T_{s}\right)$. Here, $\alpha$ represents the volumetric interphase heat-transfer coefficient which equals the product of the specific interfacial exchange area and the fluid-particle heat-transfer coefficient $\alpha_{p}$. For mono-sized spherical particles $\alpha$ can be obtained from:

$$
\alpha=\frac{6(1-\epsilon)}{d_{p}} \alpha_{p}
$$

where $\alpha_{p}$ has to be estimated from empirical correlations. There are a large number of empirical correlations available for the estimation of both packed bed and fluidized bed fluid-particle heat-transfer coefficients. In the present study, the correlation proposed by Gunn (1978) was selected to obtain an expression for the fluid-particle heat-transfer coefficient $\alpha_{p}$. This correlation relates the Nusselt-number $N u_{p}$ to the Reynolds number $R e_{p}$ and the Prandtl number $P r$ for heat transfer to fixed and fluidized beds of particles within the porosity range of 0.35 1.00. Experimental data are correlated up to $R e_{p}=10^{5}$.

$$
\begin{aligned}
N u_{p}=\frac{\alpha_{p} d_{p}}{\kappa_{f, o}}=(7 & \left.-10 \epsilon+5 \epsilon^{2}\right)\left[1+0.7(\operatorname{Re})^{0.2}(\operatorname{Pr})^{1 / 3}\right] \\
& +\left(1.33-2.40 \epsilon+1.20 \epsilon^{2}\right)\left(\operatorname{Re}_{p}\right)^{0.7}(\operatorname{Pr})^{1 / 3}
\end{aligned}
$$

where

$$
\operatorname{Re}_{p}=\frac{\epsilon \rho_{f}|\bar{u}-\bar{v}| d_{p}}{\mu_{f}}
$$




$$
\operatorname{Pr}=\frac{C_{p, f} \mu_{f}}{\kappa_{f, o}}
$$

As expected, the Nusselt number $N u_{p}$ given by Eq. $4 \mathrm{a}$ approaches 2 for an isolated particle in an infinite stagnant fluidum:

$$
\lim _{\mid \epsilon->1, R e_{p->0}}\left(N u_{p}\right)=2
$$

Several other, less evident, asymptotic conditions have also been incorporated in Eq. 4a. For a detailed discussion refer to the paper by Gunn (1978).

The use of Eq. 4 a inevitably introduces some inaccuracies in our model. However, due to the large volumetric interphase heat-transfer coefficient the difference in temperature between the phases will remain small which implies that the error due to the introduction of this empiricism can probably be neglected. Trial simulations predicted, as expected, rapid quenching of hot fluidizing air flowing into a cold fluidized bed of glass beads.

\section{Thermal conductivities $\kappa_{f}$ and $\kappa_{s}$}

The proper specification of the constitutive equations for the thermal conductivities $\kappa_{f}$ and $\kappa_{s}$ poses a major difficulty in the theoretical formulation. In terms of the TFM approach $\kappa_{f}$ and $\kappa_{s}$ must both be interpreted as effective transport properties which means that the corresponding microscopic transport coefficients $\kappa_{f, o}$ and $\kappa_{s, o}$ cannot be used. Both $\kappa_{f}$ and $\kappa_{s}$ are expected to depend on $\epsilon, \kappa_{f, o}, \kappa_{s, o}$ and the particle geometry, where the functional dependency must be specified partly by recourse to experimental data.

To derive the corresponding expressions it is necessary to consider the heat conduction terms in the thermal energy equations (T1-5) and (T1-6) in more detail. These equations show that Fourier's law of heat conduction has been used to represent the conductive heat transport in both phases. Accordingly the expressions for the conductive heat fluxes $\bar{\Phi}_{f}$ and $\bar{\Phi}_{s}$, in the fluid and the solid phase, respectively, should be formulated as:

$$
\bar{\Phi}_{f}=-\epsilon \kappa_{f} \nabla T_{f}
$$

and

$$
\bar{\Phi}_{s}=-(1-\epsilon) \kappa_{s} \nabla T_{s}
$$

In terms of the theoretical model, the total conductive heat flux $\bar{\Phi}$ can be written as follows:

$$
\bar{\Phi}=\bar{\Phi}_{f}+\bar{\Phi}_{s}=-\left\{\epsilon \kappa_{f} \nabla T_{f}+(1-\epsilon) \kappa_{s} \nabla T_{s}\right\}
$$

which reduces to:

$$
\bar{\Phi}=-\left\{\epsilon \kappa_{f}+(1-\epsilon) \kappa_{s}\right\} \nabla T=-\kappa_{m} \nabla T
$$

in case of thermodynamic equilibrium $\left(T_{f}=T_{s}=T\right)$ between the phases. Thus, according to Eq. 6d the "mixture conductivity" $\kappa_{m}$ is defined as:
This mixture conductivity $\kappa_{m}$ corresponds to the familiar "effective bed conductivity" $\kappa_{b}$ which can be determined experimentally. In the most general case, as discussed by Gelperin and Einstein (1971), this mixture or bed conductivity ( $\kappa_{m}$ or $\kappa_{b}$ ) includes conductive, convective and radiative components. However, due to its insignificance at the conditions of the present study, radiative heat transfer will not be considered further. Because, the convective transport components are accounted for separately in the thermal energy equations (T1-5) and (T1-6), they neither need further consideration. The remaining conductive transport mechanism is a very complex phenomenon involving contact conductance among the particles and conduction through a fluid layer surrounding each particle.

In the present study we use the model of Zehner and Schlünder (1970) to obtain an approximate expression for the effective thermal bed conductivity $\kappa_{b}$. This conductivity model was originally developed for the estimation of the effective radial thermal conductivity in packed beds. However, it can also be applied to estimate the effective dense phase thermal conductivity in fluidized beds (Biyikli et al., 1989). According to the Zehner and Schlünder (1970) model the radial bed conductivity $\kappa_{b}$ consists of a contribution $\kappa_{b, f}$ due only to the fluid phase and a contribution $\kappa_{b, s}$ due to a combination of the fluid phase and the solid phase:

$$
\kappa_{b}=\kappa_{b, f}+\kappa_{b, s}
$$

where

$$
\begin{gathered}
\kappa_{b, f}=(1-\sqrt{(1-\epsilon)}) \kappa_{f, o} \\
\kappa_{b, s}=\sqrt{(1-\epsilon)}\{\omega A+(1-\omega) \Gamma\} \kappa_{f, o}
\end{gathered}
$$

and

$$
\begin{gathered}
\Gamma=\frac{2}{\left(1-\frac{B}{A}\right)}\left\{\frac{(A-1)}{\left(1-\frac{B}{A}\right)^{2}} \frac{B}{A} \ln \left(\frac{A}{B}\right)\right. \\
\left.-\frac{(\mathrm{B}-1)}{\left(1-\frac{B}{A}\right)}-\frac{1}{2}(B+1)\right\} \\
B=1.25\left(\frac{(1-\epsilon)}{\epsilon}\right)^{10 / 9}
\end{gathered}
$$

for spherical particles

$$
\begin{gathered}
A=\frac{\kappa_{s, o}}{\kappa_{f, o}} \\
\omega=7.26 \times 10^{-3}
\end{gathered}
$$

Figure 1 shows the effective bed conductivity $\kappa_{b}$ as a function of the bed porosity $\epsilon$ according to the Zehner and Schlünder model for spherical glass beads in air. It is interesting to note that in the operating region of fluidized beds $(\epsilon>0.40), \kappa_{b}$ is 


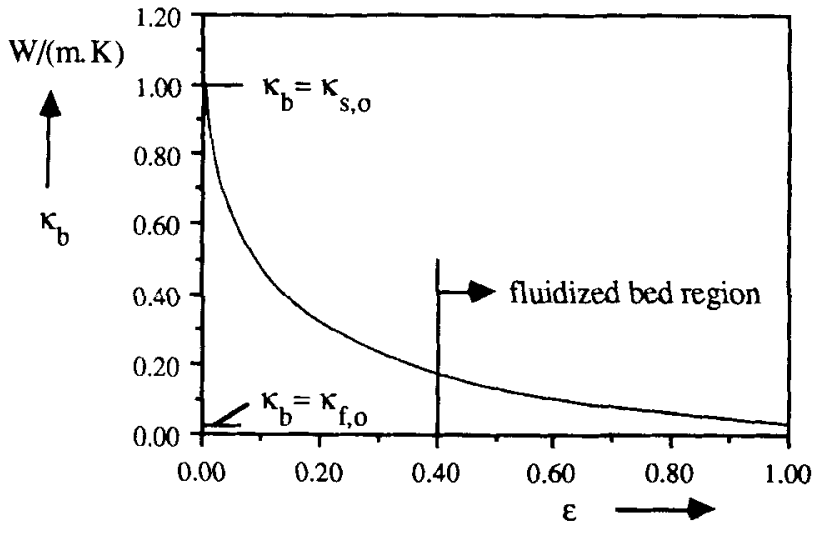

Figure 1. Effective bed conductivity $\kappa_{b}$ as a function of the bed porosity $\epsilon$ according to the Zehner and Schlünder (1970) model.

Fluid-particle system: air $\left[\kappa_{f, o}=0.0257 \mathrm{~W} /(\mathrm{m} \cdot \mathrm{K})\right]$; glass beads $\left[\kappa_{s, 0}=1.00 \mathrm{~W} /(\mathrm{m} \cdot \mathrm{K})\right]$

significantly smaller than $\kappa_{s, o}$. The desired constitutive equations for $\kappa_{f}$ and $\kappa_{s}$ can finally be obtained by comparing Eq. 6e with Eq. 7a:

$$
\begin{gathered}
\kappa_{f}=\frac{\kappa_{b, f}}{\epsilon} \\
\kappa_{s}=\frac{\kappa_{b, s}}{(1-\epsilon)}
\end{gathered}
$$

Syamlal and Gidaspow (1985) have also developed a numerical model for a hot gas-fluidized bed based on a TFM approach. They too used the Zehner and Schlünder model to obtain the constitutive equations for $\kappa_{f}$ and $\kappa_{s}$. However, their constitutive equations show some remarkable differences with the ones derived in the present study. They assumed that the fluid phase thermal conductivity $\kappa_{f}$ equals the corresponding microscopic thermal conductivity $\kappa_{f, o}$ and that the solid phase thermal conductivity $\kappa_{s}$ equals the mixture or effective thermal bed conductivity $\kappa_{b}$, thus:

$$
\kappa_{f}=\kappa_{f, o}
$$

and

$$
\kappa_{s}=\kappa_{b}
$$

In the gas-particle system considered by Syamlal and Gidaspow (1985), the bed conductivity $\kappa_{b}$ is dominated by the contribution of the solid phase $\kappa_{b, s}$ which implies that their expression for the solid phase thermal conductivity $\kappa_{s}$ differs approximately a factor $1 /(1-\epsilon)$ from the present one.

\section{Numerical Simulation}

The TFM conservation equations have been solved numerically by a finite difference technique, described in more detail by Kuipers et al. (1990). This technique has been embodied in a computer model which calculates the "primary" or basic variables in two-dimensional Cartesian or axisymmetrical cy-
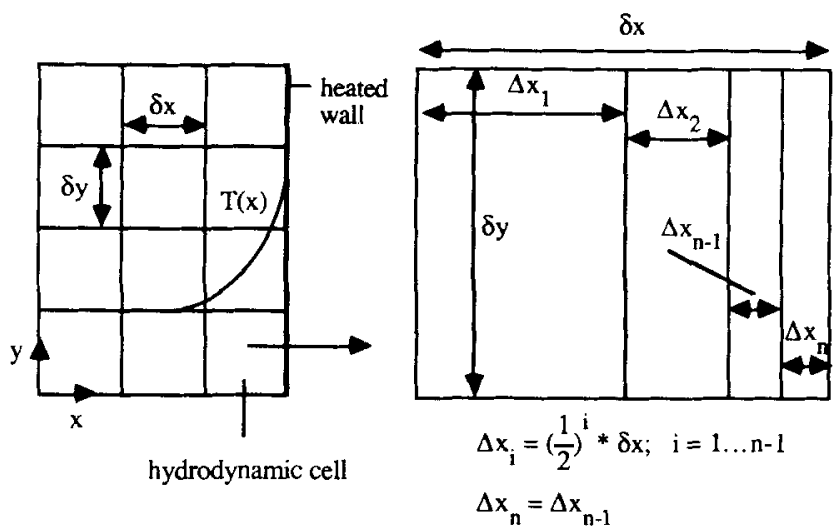

Figure 2. Subdivision of hydrodynamic computational cells into subcells near a heated wall.

$n=$ number of subcells.

lindrical coordinates. Previous work (Kuipers et al., 1991, 1992b) was concerned with the theoretical prediction of the cold-flow hydrodynamics in a two-dimensional gas-fluidized bed. In the present study the numerical model has been extended to enable the additional calculation of wall-to-bed heattransfer coefficients in fluidized beds.

Preliminary calculations showed the existence of very sharp temperature gradients near the heated wall which necessitated the use of a grid refinement technique in order to accurately represent the temperature profiles in the thin thermal boundary layer. This technique was not incorporated in the basic numerical model and will be briefly discussed below.

\section{Grid refinement technique}

While applying a finite difference technique for the solution of the complex partial differential equations, the considered region of the two-phase flow was divided into a number of equally sized cells (as shown in Figure 2). The original cell structure of the hydrodynamic model is now refined in one dimension, viz normal to the heated wall, by a subdivision as sketched in Figure 2. As Figure 2 shows, the subcell dimension normal to the heated wall $\Delta x_{i}$ decreases with decreasing distance from the wall: the finest subcells are situated immediately near the heated wall where the maximum temperature gradients are to be expected.

Syamlal and Gidaspow (1985) have used uniform subcell dimensions in their numerical model. This approach is less efficient from a computational point of view, because the total number of subcells required to achieve the same degree of grid refinement near the heated wall is considerably higher. The required number of subcells $n$ is problem dependent and should be found by performing a convergence study with respect to the numerically calculated heat-transfer coefficients. Computational experience has shown that for the conditions of the present study, division into 7 subcells is sufficient to establish a grid-independent solution.

\section{Fluid-particle system}

For the theoretical calculations reported in this article, the fluid-particle system consisted of air as the fluidizing medium and mono-sized spherical glass beads as the fluidized solid 
Table 2. Numerical Data of the Fluid-Particle System

\begin{tabular}{lll}
\hline \multicolumn{3}{c}{ Fluidizing medium: air at room temperature and l bar } \\
Density & \multicolumn{3}{c}{ ideal gas law } & $\mathrm{W} /(\mathrm{m} \cdot \mathrm{K})$ \\
Thermal conductivity & 0.0257 & $\mathrm{~J} /(\mathrm{kg} \cdot \mathrm{K})$ \\
Heat Capacity & 994.0 & $\mathrm{~m}$ \\
Fluidized solid particles: & Spherical glass beads \\
Particle diameter & $5.00 \times 10^{-4}$ & $\mathrm{~kg} / \mathrm{m}^{3}$ \\
Density & 2,660 & $\mathrm{~W} /(\mathrm{m} \cdot \mathrm{K})$ \\
Thermal conductivity & 1.00 & $\mathrm{~J} /(\mathrm{kg} \cdot \mathrm{K})$ \\
Heat capacity & 737.0 & \\
\hline
\end{tabular}

particles. The numerical data used for the computations have been summarized in Table 2.

\section{Geometry and initial conditions used for the numerical computations}

Figure 3 shows the bed geometry and the initial conditions used for the numerical computations. Other relevant data are listed in Table 3. Two-dimensional Cartesian coordinates were used for all computations reported in this article. Unless otherwise stated, the lateral and vertical dimensions of the hydrodynamic computational cells were respectively $\delta x=0.0075$ $\mathrm{m}$ and $\delta y=0.0100 \mathrm{~m}$ (required number of computational cells: $38 \times 100=3,800$ ). The time step was typically $2.5 \times 10^{-4} \mathrm{~s}$. Similar to our previous work, the initial condition of minimum fluidization was used for all computations.

A freeboard of the same size as the initial bed height $h_{m f}$ was provided to allow for bed expansion. At zero time, the velocity of the air injected through the orifice near the right wall was increased from minimum fluidization velocity $u_{m f}$ to the required orifice velocity $u_{o}$. Together with the injection of the additional fluidizing air through the orifice, the temperature of the right wall was stepwise increased from $293.0 \mathrm{~K}$ to $373.0 \mathrm{~K}$. These sudden changes in boundary conditions, imposed at the confining walls, caused the simultaneous for-
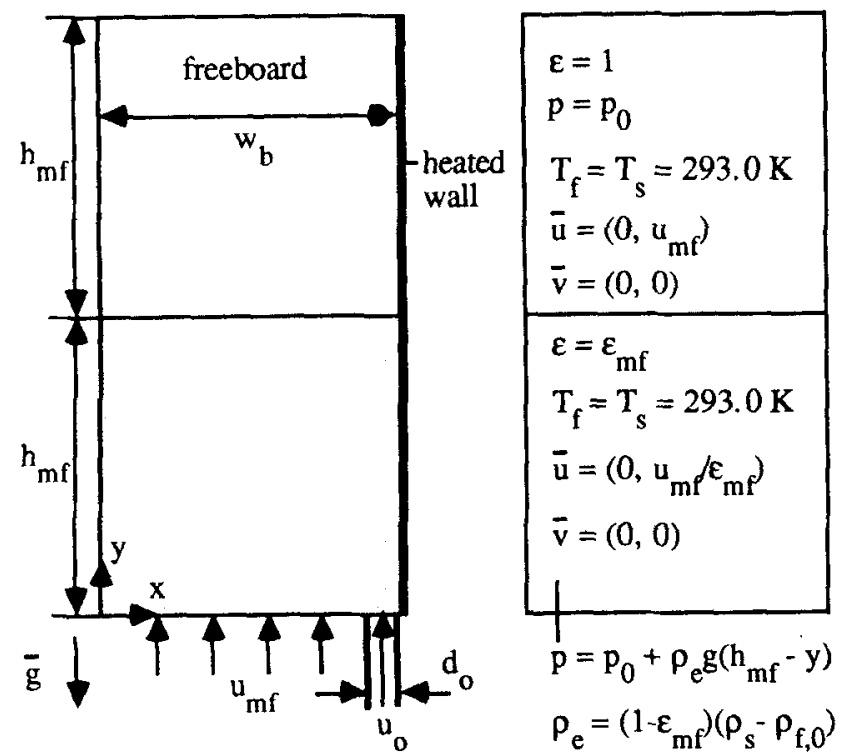

Figure 3. Bed geometry and initial conditions used for the numerical computations.
Table 3. Bed Geometry and Initial Conditions Used for the Computations

\begin{tabular}{lll}
\hline Initial bed height & 0.500 & $\mathrm{~m}$ \\
Bed width & 0.285 & $\mathrm{~m}$ \\
Orifice diameter & $1.50 \times 10^{-2}$ & $\mathrm{~m}$ \\
Minimum fluidization porosity & 0.402 & \\
Minimum fluidization velocity & 0.250 & $\mathrm{~m} / \mathrm{s}$ \\
Initial freeboard pressure & $101,325.0$ & $\mathrm{~Pa}$ \\
Bed temperature & 293.0 & $\mathrm{~K}$ \\
\hline
\end{tabular}

mation of bubbles and the penetration of heat into the fluidized bed.

\section{Boundary conditions for the hydrodynamic equations}

The left and right walls were modelled as impermeable free slip rigid walls for both phases. At the bottom wall the influx of fluidizing air was prescribed and for the solid phase a free slip rigid wall was assumed.

At the top of the bed a continuative outflow wall and an impermeable free slip rigid wall were assumed for the fluid phase and the solid phase respectively. The mathematical representation of the boundary conditions for the hydrodynamic equations is shown in Figure 4a.

\section{Boundary conditions for the thermal energy equations}

The left wall was considered to be an adiabatic wall for both phases. At the right wall a temperature $T_{w}=373.0 \mathrm{~K}$ was imposed for both phases. At the bottom wall the inlet temperature of the fluidizing air and the temperature of the solid particles were prescribed as $T_{f}=T_{s}=293.0 \mathrm{~K}$. At the top of the bed a continuative outflow wall was assumed for the fluid phase and for the solid phase an adiabatic wall was assumed. The mathematical representation of the boundary conditions for the thermal energy equations is shown in Figure $4 \mathrm{~b}$.

\section{Results}

It will be evident that it is impossible to present an extensive number of simulations due to the large number of parameters which can be varied. Furthermore, each simulation requires a huge amount of computer time which imposes a practical constraint to keep the total computational time reasonable. Therefore, only a few typical situations have been studied.

\section{Bed at minimum fluidization conditions}

First, a fluidized bed operated at minimum fluidization conditions has been considered in our numerical study since it is amenable to a simple theoretical analysis as shown below. Advantageously, on the one hand, the validation of the numerical solution method can be obtained by comparing the model predictions with the results of this theoretical analysis, on the other hand, a "base case solution" becomes available which is very useful in order to place the computational results for more complicated systems in perspective.

Simple Theoretical Model. For an incipiently fluidized bed, the thermal energy equations (T1-5) and (T1-6) reduce to: 


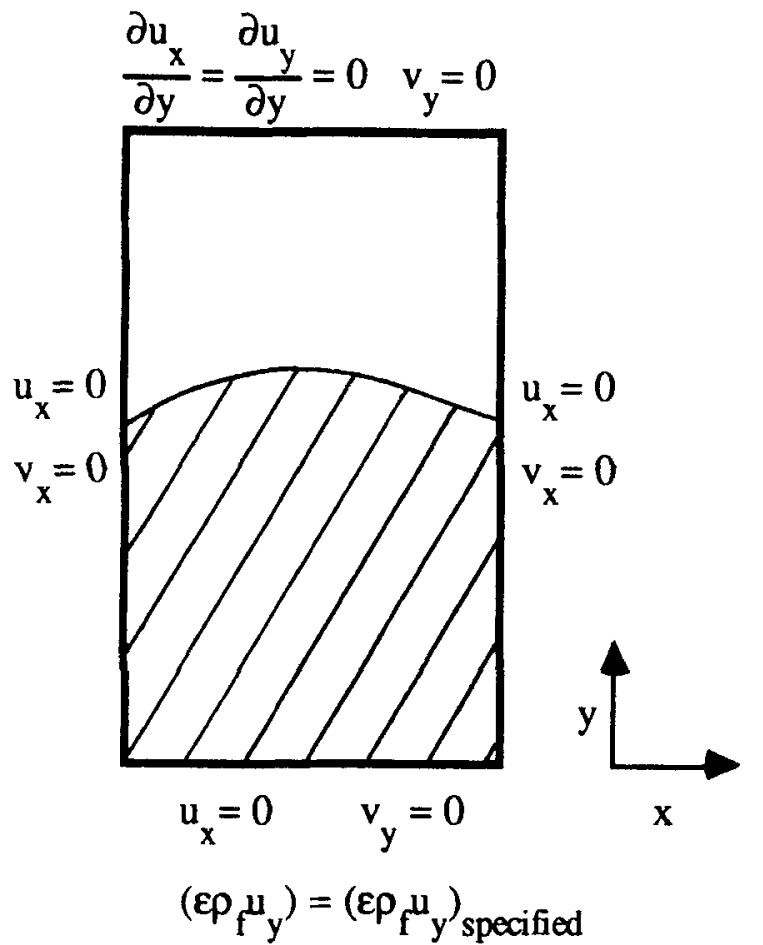

Figure 4a. Boundary conditions for the hydrodynamic equations.

$$
\frac{\partial}{\partial t}\left(\epsilon \rho_{f} C_{p, f} T_{f}\right)=\frac{\partial}{\partial x}\left[\epsilon K_{f}\left(\frac{\partial T_{f}}{\partial x}\right)\right]-\alpha\left(T_{f}-T_{s}\right)
$$

and

$$
\frac{\partial}{\partial t}\left[(1-\epsilon) \rho_{s} C_{p, s} T_{s}\right]=\frac{\partial}{\partial x}\left[(1-\epsilon) \kappa_{s}\left(\frac{\partial T_{s}}{\partial x}\right)\right]+\alpha\left(T_{f}-T_{s}\right)
$$

respectively, provided that, first, both the convective heat transport and the work terms can be neglected and, secondly, that the conductive heat transport predominantly occurs normal to the heated wall (that is, in the $x$-direction). In the case of local thermodynamic equilibrium $\left(T_{f}=T_{s}=T\right)$ between the phases and constant thermophysical properties near the heated wall, Eqs. 10a and $10 \mathrm{~b}$ reduce to:

$$
\frac{\partial T}{\partial t}=a_{e} \frac{\partial^{2} T}{\partial x^{2}}
$$

which is the well-known heat conduction equation. Here, $a_{e}$ represents the mixture or effective thermal diffusivity defined by:

$$
a_{e}=\frac{\epsilon \kappa_{f}+(1-\epsilon) \kappa_{s}}{\epsilon \rho_{f} C_{p, f}+(1-\epsilon) \rho_{s} C_{p, s}}=\frac{\kappa_{m}}{\left(\rho C_{p}\right)_{m}}
$$

For a semi-infinite medium, the familiar penetration theory solution can be obtained from Eq. 11. According to the penetration theory the local instantaneous heat-transfer coef ficient $h_{i}$ is given by:

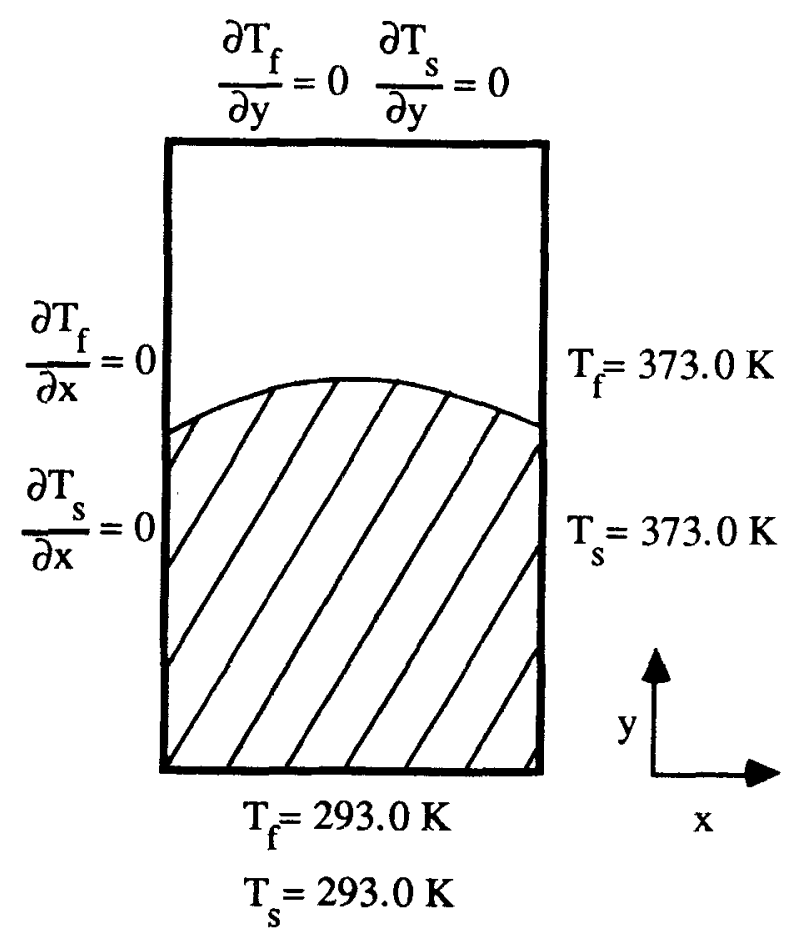

Figure 4b. Boundary conditions for the thermal energy equations.

$$
h_{i}=\sqrt{\frac{\kappa_{m}\left(\rho C_{p}\right)_{m}}{\pi t}}
$$

For many purposes it is useful to consider also the average heat-transfer coefficient $h$ during a certain contact time $t_{p}$. From its definition and Eq. 13 it can easily be shown that $h$ is given by:

$$
h=2 \sqrt{\frac{\kappa_{m}\left(\rho C_{p}\right)_{m}}{\pi t_{p}}}
$$

For the fluid-particle system considered in the present study Eqs. 13 and 14 yield respectively:

$$
h_{i}=\frac{252}{\sqrt{t}}\left[W /\left(m^{2} \cdot K\right)\right]
$$

and

$$
h=\frac{504}{\sqrt{t_{p}}}\left[W /\left(m^{2} \cdot K\right)\right]
$$

Equations 15 and 16 will subsequently be used for the interpretation of the computational results.

As a typical example, Figure 5 shows the numerically calculated local wall-to-bed heat-transfer coefficient as a function of time for an incipiently air-fluidized bed at a height of approximately $0.24 \mathrm{~m}$ above the gas distributor. The prediction according to the penetration theory, Eq. 15, is also shown in this figure. It can be seen that, in accordance with the predictions from the penetration theory, the numerically calcu- 


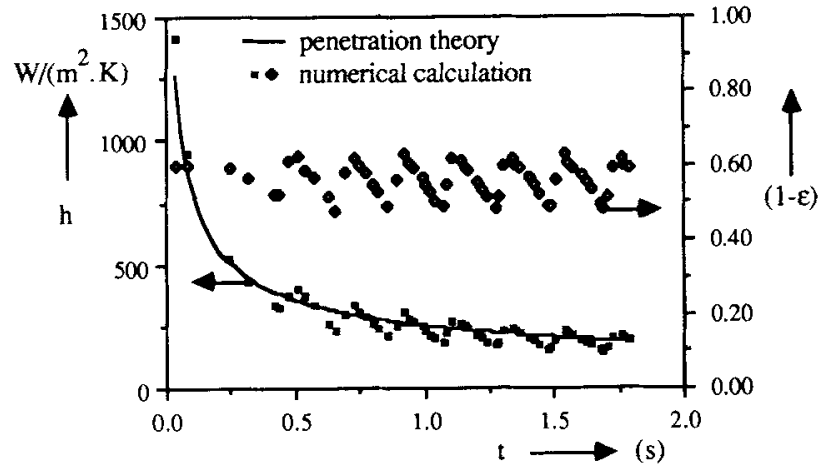

Figure 5. Numerically calculated local wall-to-bed heattransfer coefficient $h$ and local solidity $(1-\epsilon)$ as a function of time $t$ for an incipiently air. fluidized bed at approximately $0.24 \mathrm{~m}$ above the gas distributor.

At zero time the heated wall contacts the bed. Solid line: penetration theory, Eq. 15.

lated local wall-to-bed heat-transfer coefficient $h$ decreases rapidly with increasing time $t$. However, the numerically calculated local heat-transfer coefficient shows a decay with a small superimposed oscillation. At other heights above the gas distributor, similar results were obtained.

In order to find an explanation for this phenomenon, a further analysis of the computational results was performed. It was found that the local heat-transfer coefficient oscillates in phase with the computed local solidity (that is, the solid phase volume fraction $(1-\epsilon)$ ) as Figure 5 shows (oscillation frequency is approximately five $\mathrm{Hz}$ ). One might expect this finding because the group $\kappa_{m}\left(\rho C_{p}\right)_{m}$ in Eq. 13 increases with increasing solidity $(1-\epsilon)$. Although Eq. 13 was derived for constant thermophysical properties it is still applicable since the solidity fluctuations remain small. Figure 6 shows the porosity $\epsilon$ as a function of the distance $y$ above the gas distributor at $t=0.81 \mathrm{~s}$ and $t=0.89 \mathrm{~s}$. This figure clearly illustrates the propagation of voidage waves through the bed, a feature which will be explained subsequently.

It should be realized that the condition of incipient fluidi-

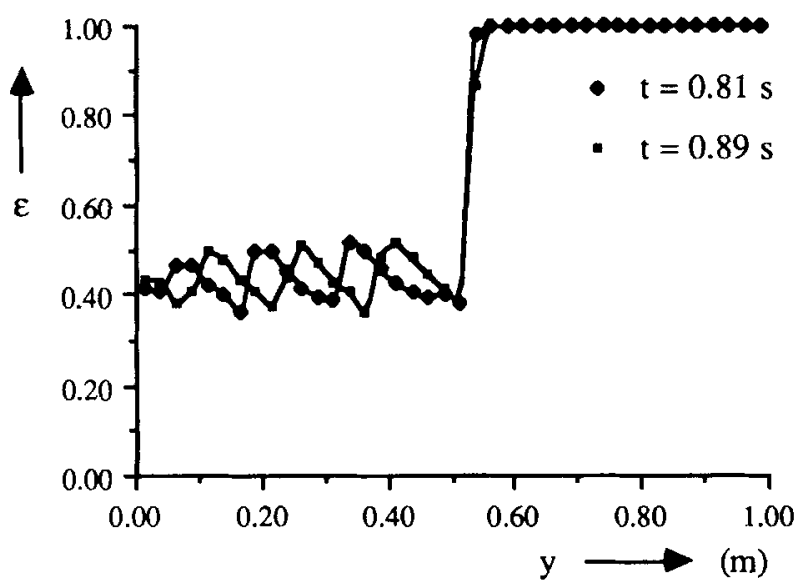

Figure 6. Propagation of small voidage waves in an incipiently air-fluidized bed.

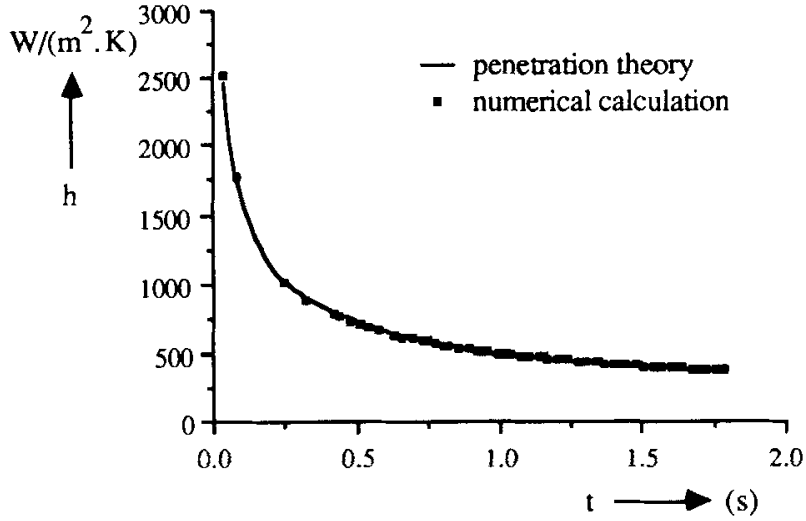

Figure 7. Time-averaged wall-to-bed heat-transfer coefficient $h$ as a function of time $t$ for an incipi. ently air-fluidized bed.

Solid line: penetration theory, Eq. 16

zation involves a very delicate balance between the frictional force exerted by the fluidizing gas on each particle and the gravitational force acting on each particle. The value of the minimum fluidization velocity $u_{m f}$ used in the simulations was slightly higher than the value corresponding to an equilibrium between frictional and gravitational forces (that is, the "true" minimum fluidization velocity). As a consequence of this small positive deviation from the "true" minimum fluidization velocity local bed expansion occurs generating a local deviation from the specified incipient fluidization porosity. As known from linear stability analysis this constitutes an instable situation and consequently the "disturbance" grows to a certain extent while propagating through the bed. In the computation this phenomenon manifests itself by the propagation of plane voidage waves through the bed spanning the entire column width. In practice, with the exception of liquid-fluidized beds where this phenomenon has been observed experimentally, due to bed inhomogeneities and small deviations from uniform gas throughflow, plane voidage waves do not occur and instead small bubbles are generated.

Figure 7 shows the time-averaged wall-to-bed heat-transfer coefficient $h$ as a function of time $t$. Prior to time-averaging, the average instantaneous wall-to-bed heat-transfer coefficient was calculated by integrating the local heat-transfer coefficients over the incipient fluidization bed height $h_{m f}$. The prediction according to the penetration theory, Eq. 16, is included in this figure. As Figure 7 shows, the numerically calculated wall-to-bed heat-transfer coefficients agree very well with the simple penetration theory solution which validates the numerical solution method.

In order to demonstrate the further capabilities of the present continuum model, a few more complicated systems have been studied theoretically and these will be discussed below.

\section{Single bubble rising along a heated wall}

The next application of the model involves the calculation of local wall-to-bed heat-transfer coefficients for the case of a single bubble rising along a heated wall. In comparison with an incipiently fluidized bed one might expect an enhancement of the wall-to-bed heat-transfer due to the bubble induced replacement of solid particles adjacent to the heat exchange sur- 

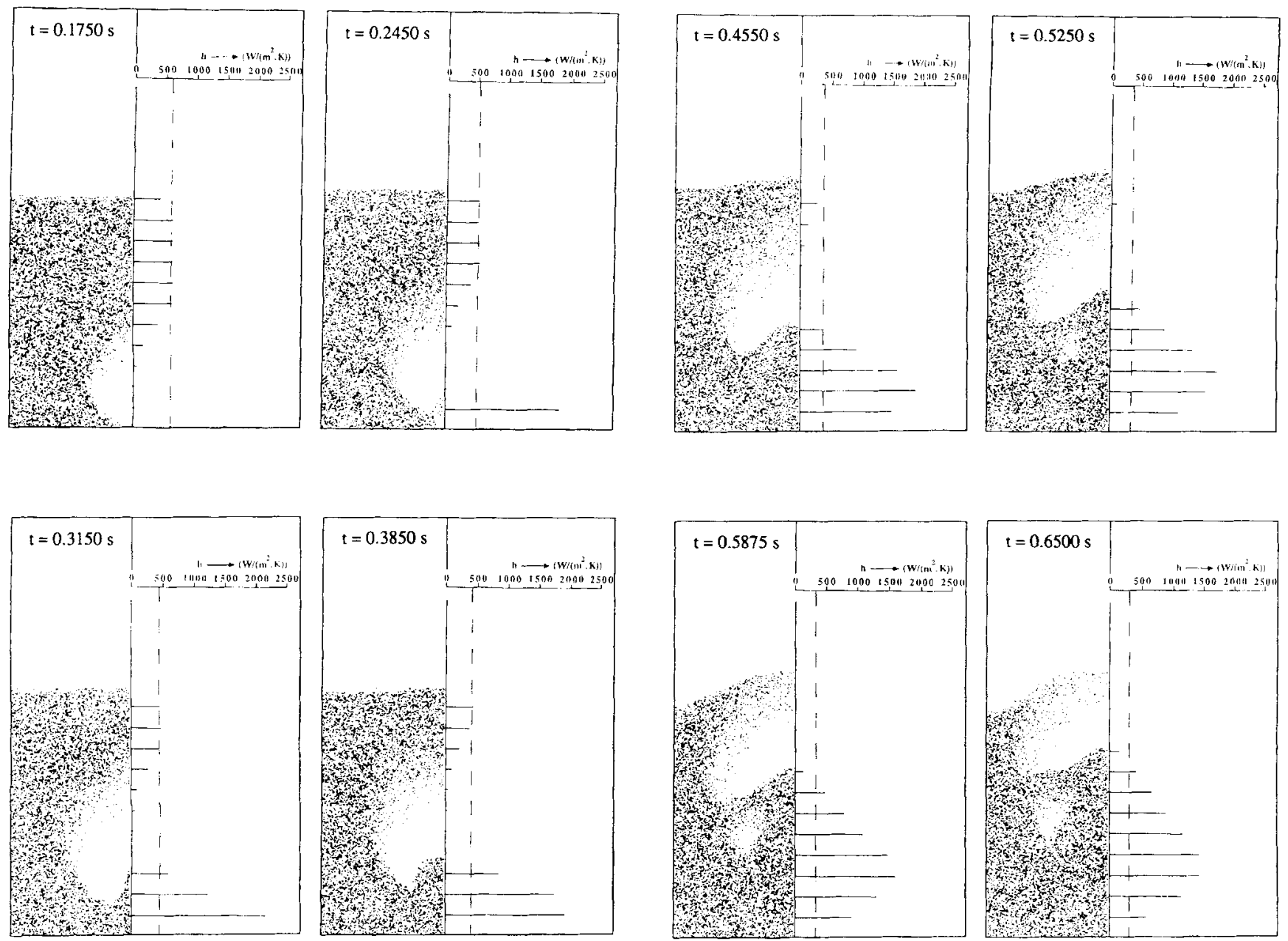

Figure 8. A bubble rising along a heated wall in a two-dimensional air-fluidized bed: a (left) and b (right).

The length of the horizontal bar designates the instantaneous local heat-transfer coefficient. Dashed line: penetration theory, Eq. 15.

face. In freely bubbling beds this solid particle replacement occurs due to the bubble induced macroscopic (that is, on the scale of the bed) solids circulation on the one hand and due to the particle motion in the immediate vicinity of rising bubbles on the other hand. The experimentally observed high heattransfer coefficients in freely bubbling beds are partly attributed to these phenomena. Here, as mentioned above, the effect of bubbles on the wall-to-bed heat transfer in fluidized beds, will be studied computationally in its simplest form.

The injection of a single bubble into an incipiently fluidized bed was simulated by limiting the time of additional (that is, in excess of the incipient fluidization velocity $u_{m f}$ ) air injection to $0.245 \mathrm{~s}$. The injection velocity of the additional air was 5.25 $\mathrm{m} / \mathrm{s}\left(21^{*} u_{m f}\right)$ for $0<t<0.245 \mathrm{~s}$ and $0.25 \mathrm{~m} / \mathrm{s}\left(u_{m f}\right)$ for $t>0.245$ s. Figures $8 \mathrm{a}$ and $8 \mathrm{~b}$ show a sequence of density or dot plots which clearly illustrate the bubble formation, the bubble rise along the (heated) wall and the eruption at the bed interface. A visual representation of the numerically calculated instantaneous local heat-transfer coefficients is included in these figures. Here, the length of the horizontal bar is a measure for the value of the instantaneous local heat-transfer coefficient. The dashed line represents the prediction according to the penetration theory, Eq. 15, which has been included for the purpose of reference.
As Figure 8a shows, after $0.245 \mathrm{~s}$ of air injection a bubble has detached from the orifice. During its rise along the wall, the bubble shape changes continuously due to the development of its wake. In front of the rising bubble, the calculated local heat-transfer coefficients are relatively low and decrease, as expected, with increasing time. However, at the rear of the rising bubble, the calculated local heat-transfer coefficients are relatively high and differ greatly from the simple penetration theory solutions.

Evidently, the bubble induced bed material refreshment along the heated wall, which is not accounted for in the penetration theory, is responsible for these high heat-transfer rates. This effect can be recognized very clearly from the first two plots (at $t=0.1750 \mathrm{~s}$ and at $t=0.2450 \mathrm{~s}$ ) of Figure $8 \mathrm{a}$. The local heattransfer coefficient increases sharply as soon as the bed material, constituting the developing bubble wake, hits the heated wall. From the plots shown in Figure $8 \mathrm{~b}$ it can further be seen that the maximum heat transfer occurs at some distance behind the rising bubble. Figure 9 shows the calculated instantaneous local heat-transfer coefficients as a function of time at four different heights above the gas distributor.

At heights less than the initial bed height, $y<h_{m j}$, the transient behavior is very similar in all cases. Initially the numerically calculated heat-transfer coefficients decay rapidly with 


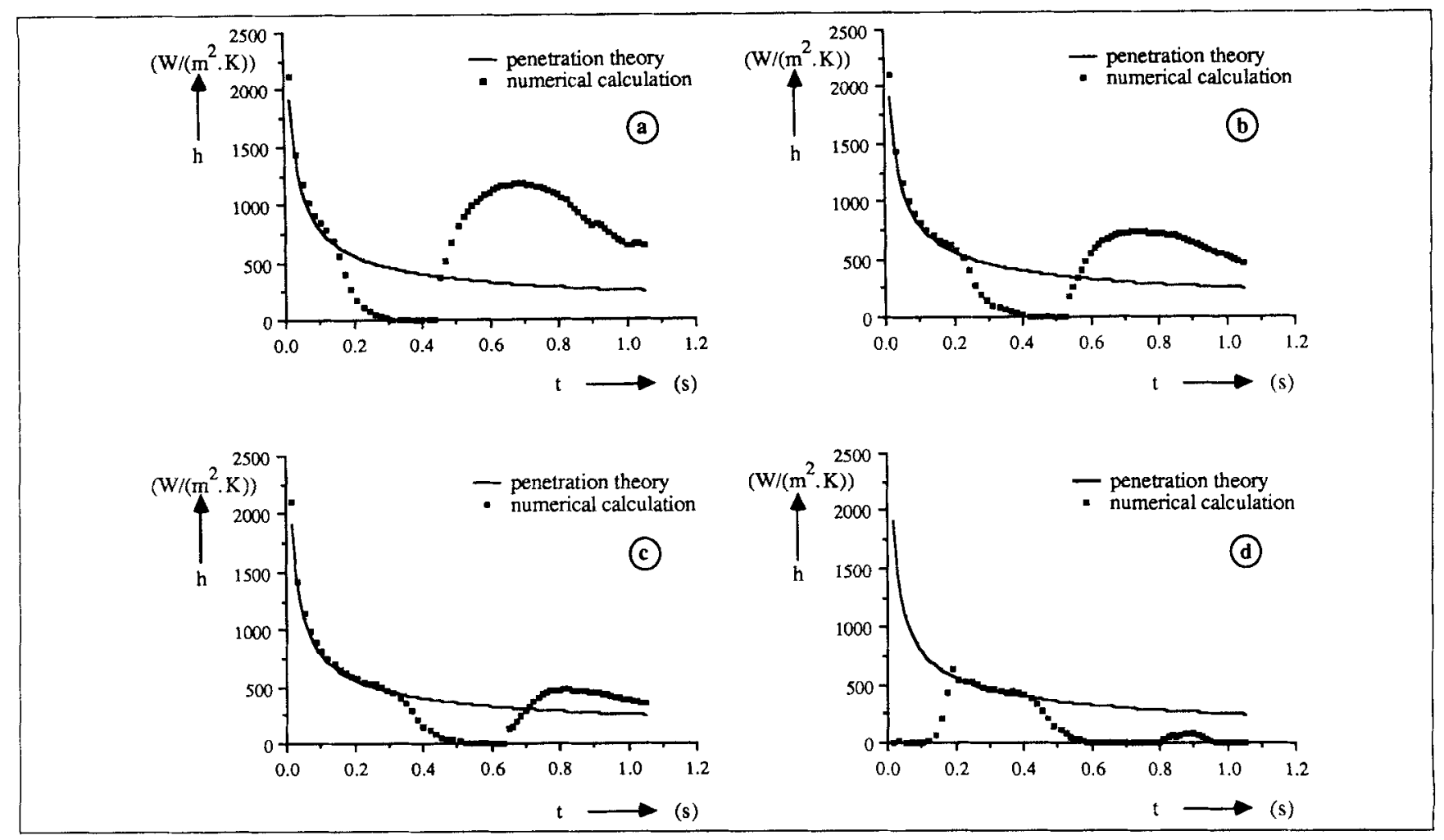

Figure 9. Calculated instantaneous local heat-transfer coefficients as a function of time at four different heights above the gas distributor: (a) $y=0.245 \mathrm{~m}$; (b) $y=0.345 \mathrm{~m}$; (c) $y=0.445 \mathrm{~m}$; (d) $y=0.545 \mathrm{~m}$.

Initial bed height: $h_{m f}=0.500 \mathrm{~m}$. Solid line: penetration theory solution, Eq. 15 .

increasing time and they practically coincide with the penetration theory solution, Eq. 15. One might expect these results, since for short simulation times, the principal wall-to-bed heat transfer occurs through transient conduction normal to the heated wall into a nearly stagnant emulsion phase.

At each location, as soon as the rising bubble passes, a drastic decrease of the numerically calculated local heat-transfer coefficient can be observed due to the relatively low effective thermal conductivity inside the bubble. After the bubble passage, the local heat-transfer coefficient rises sharply, passes through a maximum, and then slowly decreases again. From Figure 9 it can be seen that the magnitude of this maximum decreases with increasing height above the gas distributor. This phenomenon is probably related to the progressive heat penetration into the emulsion phase constituting the bubble wake. The calculated heat-transfer coefficient, at $y=0.545 \mathrm{~m}\left(>h_{m f}\right)$ above the gas distributor, reflects the combined effects of the bed expansion and the subsequent bed collapse.

In Figure 10, the instantaneous average wall-to-bed heattransfer coefficient, which was obtained by integrating the local heat-transfer coefficients over the incipient fluidization bed height $h_{m f}$, is shown as a function of time. The penetration theory solution, Eq. 15, is also shown in this figure. Initially, the calculated average wall-to-bed heat-transfer coefficient coincides with the penetration theory solution, however, during the final stage of bubble formation the available effective heat exchange length has decreased substantially due to the presence of the bubble and as a consequence, the average wall-to-bed heat-transfer coefficient falls below the penetration theory solution, Eq. 15.
During its rise along the heated wall, the bubble induces a refreshment of the bed material adjacent to this wall and eventually the calculated average wall-to-bed heat-transfer coefficient exceeds the penetration theory solution. Obviously the phenomenon of bed material refreshment overcompensates for the loss of the available effective heat exchange length due to the presence of the bubble.

\section{Stream of bubbles rising along a heated wall}

In the previous section, the effect of bubbles on the wall-

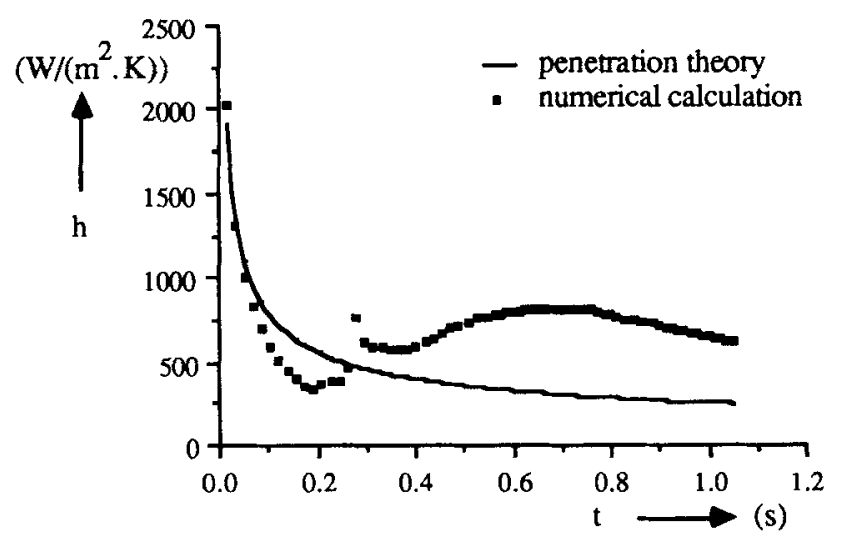

Figure 10. Instantaneous average wall-to-bed heattransfer coefficient as a function of time.

Solid line: penetration theory solution, Eq. 15. 

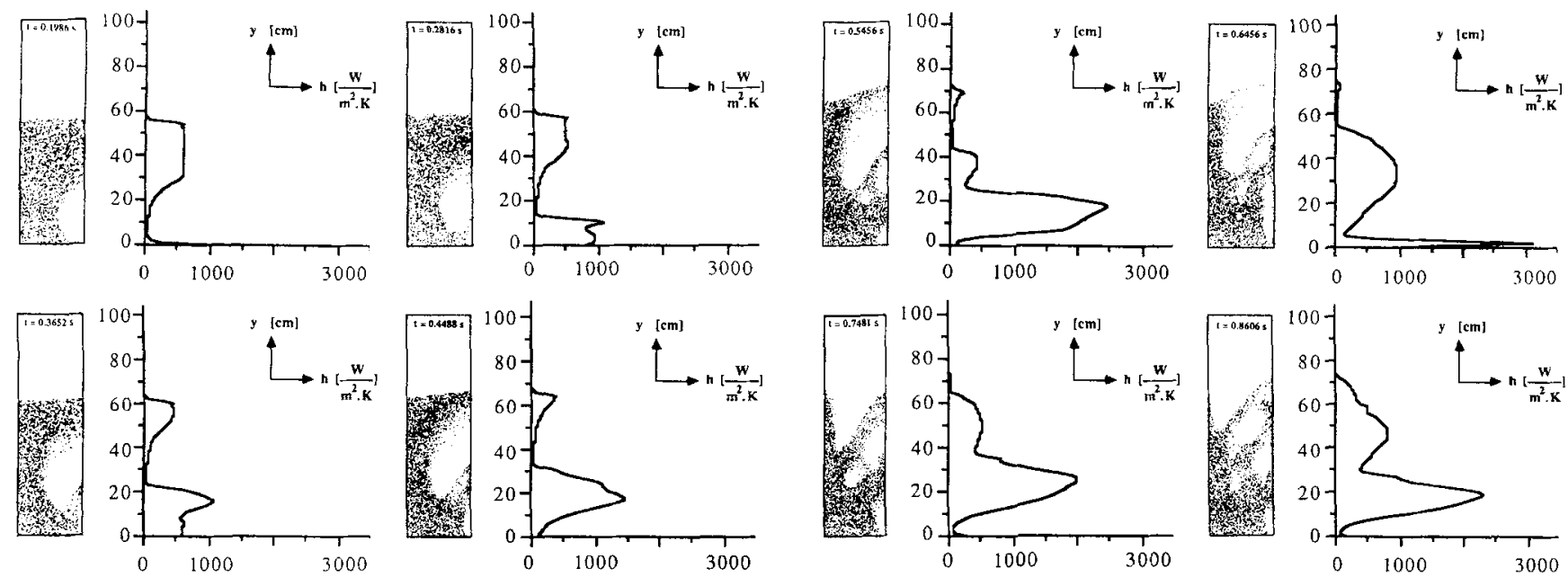

Figure 11. Evolution and propagation of bubbles in a two-dimensional air-fluidized bed with a heated wall: a (left) and $b$ (right).

The bubbles originate from an orifice near the heated right wall. Air injection velocity through the orifice: $5.25 \mathrm{~m} / \mathrm{s}\left(21^{*} u_{m f}\right)$.

to-bed heat-transfer in fluidized beds was studied computationally in its simplest form by considering a single injected bubble rising along a heated wall. The maximum heat transfer occurred at some distance behind the rising bubble due to the significant bed material refreshment in the bubble wake. Despite the simplicity of the system considered in the previous section, it seems reasonable that the experimentally observed large wall-to-bed heat-transfer coefficients of freely bubbling beds are determined partly by very similar phenomena.

Unfortunately, at present it is impossible to simulate such freely bubbling fluidized beds and the corresponding wallto-bed heat-transfer processes on the basis of mechanistic models since such simulations would require a very large number of computational cells and consequently huge amounts of (super-) computer time. Once the extension of the present twodimensional numerical model to a three-dimensional one has been achieved, this limitation constitutes a practical limitation only. Hereafter, an approximately situation will be considered.

A two-dimensional bed with preferential bubble formation near a heated wall served as a very rough approximation of a freely bubbling bed with an immersed vertical heat-exchanger tube. The injection velocity of the additional air (that is, in excess of the incipient fluidization velocity $u_{m f}$ ) was kept constant at $5.25 \mathrm{~m} / \mathrm{s}\left(21^{*} u_{m f}\right)$ in this final application of our continuum model.

Figures $11 \mathrm{a}$ and $11 \mathrm{~b}$ show a sequence of density or dot plots which illustrate the formation, the rise along the heated wall and the subsequent collapse at the bed interface of the first bubbles, generated by the injection of the additional air through the orifice near the hot wall. A visual representation of the numerically calculated instantaneous local heat-transfer coefficients is included in these figures. During the initial period, the evolution and propagation of a relatively big start-up bubble can be clearly seen from Figure 11a. Subsequently, the simulation predicts the evolution and propagation of small elongated bubbles which tend to move away from the heated wall with increasing height above the gas distributor (See Figure 11b). Inspection of Figure 11a shows again that the maximum wall-to-bed heat-transfer occurs in the bubble wake. This phenomenon was also observed in the previous section.
Figure $11 \mathrm{~b}$ shows the presence of several bubbles, and as a consequence the profile of the instantaneous heat-transfer coefficient along the hot wall displays several maxima. As expected on the basis of the results presented in the previous section, the local heat-transfer coefficient rises very sharply if the bed material of the developing bubble wake hits the heated wall. This effect can be seen very clearly from the second plot (at $t=$ $0.6456 \mathrm{~s}$ ) shown in Figure $11 \mathrm{~b}$. Just above the gas distributor, the instantaneous local heat-transfer coefficient exceeds the value of $3,000 \mathrm{~W} /\left(\mathrm{m}^{2} \cdot \mathrm{K}\right)$. Conceptually, the heat-transfer process during the short bed material contact times with the heated wall, between the successive passage of bubbles, shows some resemblance with the picture envisaged in the familiar emulsion phase or packet renewal models. In terms of the packet renewal models, such high heat-transfer coefficients imply very short residence times of the "packets" or emulsion phase. At relatively short contact times the heat penetration depth will be relatively small and as a consequence, as explained in more detail in the introductory section, the effect of the altered thermophysical properties near the heated wall become important. In practice, this phenomenon will determine the maximum attainable wall-to-bed heat-transfer rates in fluidized beds. However, the present continuum model does not account for the altered thermophysical properties near the heat-transfer surface and as a consequence it probably overpredicts the actual heattransfer coefficients at very low "packet" residence times.

Figure 12 shows the calculated instantaneous heat-transfer coefficient as a function of time at $0.345 \mathrm{~m}$ above the gas distributor. The prediction according to the penetration theory, Eq. 15, is included in this figure. After the sharp initial decay and the decrease due to the passage of the big start-up bubble, the local heat-transfer coefficient vs. time exhibits a complex oscillatory behavior. Here, the tendency of the small bubbles to move away from the heated wall while they rise along it, accounts for the relatively high minimum heat-transfer rates for $t>0.5 \mathrm{~s}$. Figure 13 shows the instantaneous average wallto-bed heat-transfer coefficient as a function of time. It has been obtained according to the procedure described in the previous section. During the initial period, the heat penetrates into a nearly stagnant bed and consequently the numerically cal- 


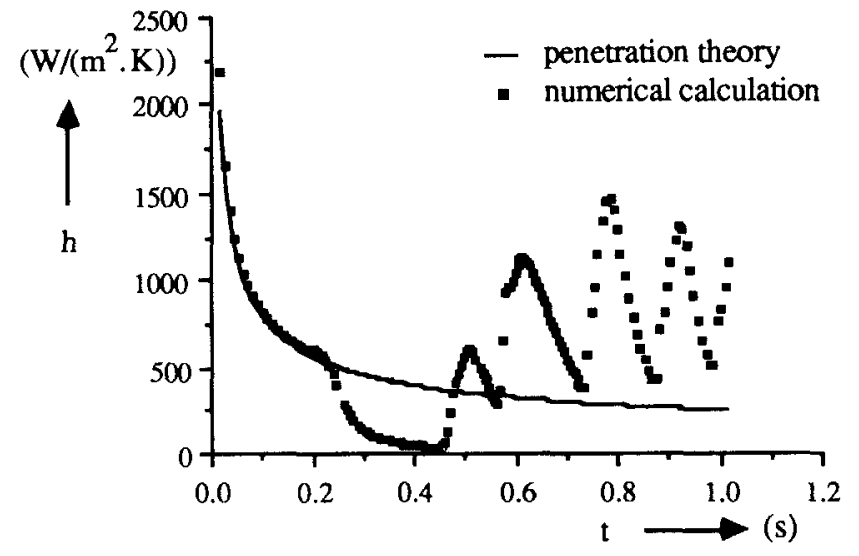

Figure 12. Calculated instantaneous heat-transfer coefficient as a function of time at $0.345 \mathrm{~m}$ above the gas distributor.

Solid line: penetration theory solution, Eq. 15.

culated heat-transfer coefficients agree with those predicted by the penetration theory. Subsequently, the average wall-to-bed heat-transfer coefficient falls below the penetration theory solution. This is caused by the presence of the big start-up bubble which substantially reduces the available effective heat exchange length. Eventually, the bubble induced bed material refreshment overcompensates for this phenomenon and the calculated average wall-to-bed heat-transfer coefficient exceeds the penetration theory solution. The instantaneous average wall-to-bed heat-transfer coefficient vs. time exhibits a complex oscillatory behavior which cannot be predicted with the simple penetration theory.

Furthermore, as Figure 12 illustrates, the present model provides detailed information on the local behavior of the wallto-bed heat-transfer coefficients. Such information cannot easily be verified by experimental methods presently available. Average wall-to-bed heat-transfer coefficients for air-fluidized glass beads have been determined experimentally by, for example, Ozkaynak and Chen (1980), Wunder (1980) and Prins (1987) in three-dimensional freely bubbling beds. A comparison of the calculated average wall-to-bed heat-transfer coef-

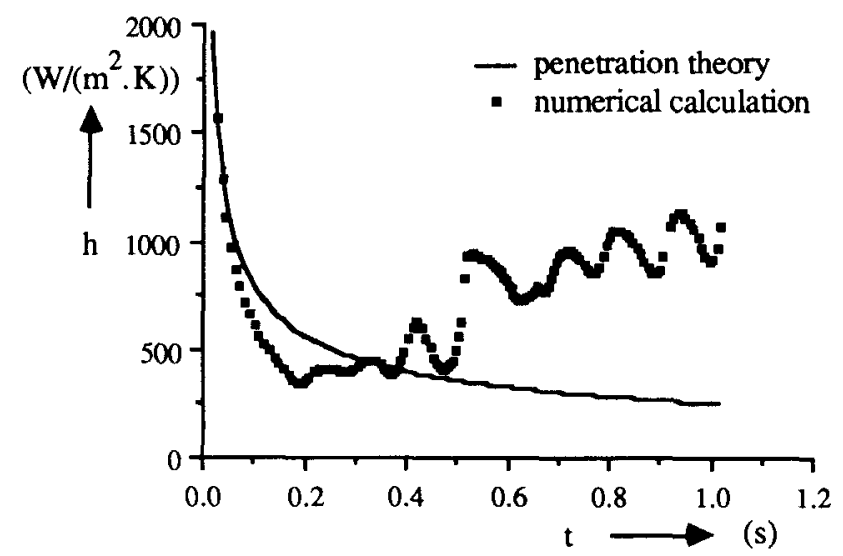

Figure 13. Instantaneous average wall-to-bed heattransfer coefficient as a function of time.

Solid line: penetration theory solution, Eq. 15. ficient with such experimental data is not attempted here, because of the large differences in conditions between the present numerical calculation and the experiments [that is, a twodimensional bed with preferential bubble formation and bubble propagation near the heated wall vs. a three-dimensional freely bubbling bed with an immersed cylindrical heater $(\mathrm{Oz}$ kaynak and Chen, 1980; Wunder, 1980) or with immersed spheres (Prins, 1987)]. Plans have been made to validate the present heat-transfer model experimentally in a two-dimensional gas-fluidized bed with a geometry very similar to the one sketched in Figure 3.

\section{Conclusions}

An earlier developed first principles hydrodynamic model has been extended to enhance the future numerical calculation of wall-to-bed heat-transfer coefficients in gas-fluidized beds. The theoretical model utilizes a TFM approach in which both phases are considered to be continuous and fully interpenetrating.

Contrary to the well-known discrete particle models and the emulsion phase or packet renewal models, the present model does not require the input of empirical parameters such as the average particle or packet residence time since the bed hydrodynamics evolves naturally from the solution of the TFM conservation of mass and momentum equations.

Our preliminary calculations, carried out for an idealized two-dimensional bed geometry, suggest that the high wall-tobed heat-transfer rates characteristic of gas-fluidized beds can be predicted with the present model without incorporation of turbulence terms in the transport equations. Through its ability to provide detailed information on the local behavior of the wall-to-bed heat-transfer coefficients, the model proves its usefulness and distinguishes itself advantageously from previous theoretical models. For the case of a single bubble rising along a heated wall it has been shown computationally that the maximum wall-to-bed heat transfer occurs in the bubble wake. In a two-dimensional bed with preferential (multiple) bubble formation near a heated wall, a very similar phenomenon was predicted. In order to extend the validity of the present continuum model to very low "packet" residence times, it will be necessary to account for the altered thermophysical properties in the immediate vicinity of the heat-transfer surface, where, for example, the porosity in the emulsion phase is higher.

\section{Acknowledgment}

This investigation was supported by VEG-Gasinstituut B. V. of the Netherlands, the central technical institute of the Dutch gas supply companies.

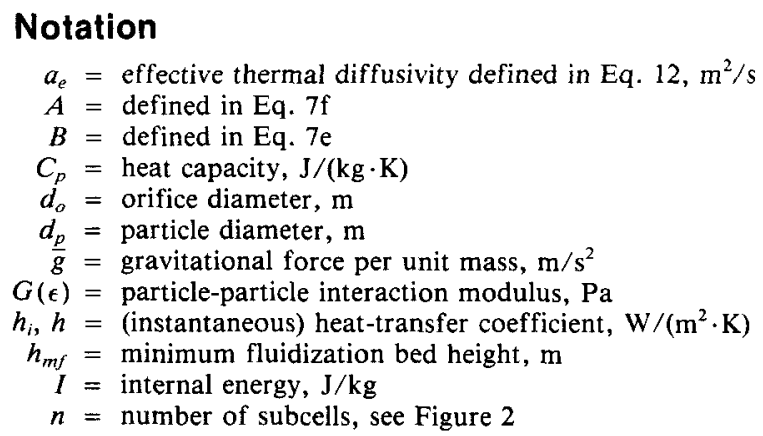


$N u_{p}=$ particle Nusselt number

$p=$ pressure, $\mathrm{Pa}$

$p_{0}=$ initial freeboard pressure, $\mathrm{Pa}$

$\operatorname{Pr}=$ Prandtl number

$R e_{p}=$ particle Reynolds number

$t=$ time, $\mathrm{s}$

$t_{p}=$ contact time of packet, $\mathrm{s}$

$T=$ temperature, $\mathrm{K}$

$\bar{u}=$ fluid-phase velocity, $\mathrm{m} / \mathrm{s}$

$u_{m f}=$ minimum fluidization velocity, $\mathrm{m} / \mathrm{s}$

$u_{o}=$ superficial injection velocity through orifice, $\mathrm{m} / \mathrm{s}$

$u_{x}=$ lateral fluid-phase velocity, $\mathrm{m} / \mathrm{s}$

$u_{y}=$ vertical fluid-phase velocity, $\mathrm{m} / \mathrm{s}$

$\bar{v}=$ solid-phase velocity, $\mathrm{m} / \mathrm{s}$

$v_{x}=$ lateral solid-phase velocity, $\mathrm{m} / \mathrm{s}$

$v_{y}=$ vertical solid-phase velocity, $\mathrm{m} / \mathrm{s}$

$w_{b}=$ bed width, $\mathrm{m}$

$x=$ lateral coordinate, $\mathrm{m}$

$y=$ vertical coordinate, $\mathrm{m}$

\section{Greek letters}

$\alpha=$ volumetric interphase heat-transfer coefficient, $\mathrm{W} /\left(\mathrm{m}^{3} \cdot \mathrm{K}\right)$

$\alpha_{p}=$ fluid-particle heat-transfer coefficient, $\mathrm{W} /\left(\mathrm{m}^{2} \cdot \mathrm{K}\right)$

$\beta=$ volumetric interphase momentum transfer coefficient, $\mathrm{kg} /$ $\left(\mathrm{m}^{3} \cdot \mathrm{s}\right)$

$\delta=$ heat penetration depth, $\mathrm{m}$

$\delta x=$ lateral computational cell dimension, $\mathrm{m}$

$\delta y=$ vertical computational cell dimension, $\mathrm{m}$

$\Delta x_{i}=$ subcell dimension normal to the heated wall, see Figure 2, $\mathrm{m}$

$\epsilon=$ porosity

$\epsilon_{m f}=$ minimum fluidization porosity

$\bar{\Phi}=$ heat flux by thermal conduction, $\mathrm{W} / \mathrm{m}^{2}$

$\Gamma=$ defined in Eq. 7d

$k=$ thermal conductivity, $\mathrm{W} /(\mathrm{m} \cdot \mathrm{K})$

$\mu=$ viscosity, $\mathrm{kg} /(\mathrm{m} \cdot \mathrm{s})$

$\rho=$ density, $\mathrm{kg} / \mathrm{m}^{3}$

$\omega=$ defined in Eq. $7 \mathrm{~g}$

\section{Subscripts}

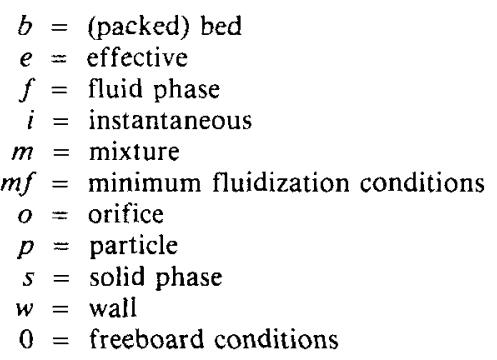

\section{Superscripts}

- vector quantity

\section{Literature Cited}

Baskakov, A. P., "Transfer of Heat from an Isothermal Surface to a Continuous Flow of Dispersed Medium," Heat Transf. Sov. Res., 1(6), 103 (1969).

Biyikli, S., K. Tuzla, and J. C. Chen, "A Phenomenological Model for Heat Transfer in Freeboard of Fluidized Beds," Can. J. Chem. Eng., 67, 230 (1989).

Botterill, J. S. M., and J. R. Williams, "The Mechanism of Heat Transfer to Gas Fluidized Beds," Trans. Instn. Chem. Engrs, , 41, 217 (1963).

Botterill, J. S. M., and M. H. D. Butt, “Achieving High Heat-Transfer Rates in Fluidized Beds," Br. Chem. Eng., 13, 1000 (1968).

Gabor, J. D., "Wall-to-Bed Heat Transfer in Fluidized and Packed Beds," Chem. Eng. Prog. Symp. Ser., 66(105), 76 (1970).

Gelperin, N. I., and V. G. Einstein, "Heat Transfer in Fluidized Beds," Fluidization, J. F. Davidson and D. Harrison, eds., Academic Press, p. 471 (1971).

Gunn, D. J., "Transfer of Heat or Mass to Particles in Fixed and Fluidized Beds," Int. J. Heat Mass Transf., 21, 467 (1978).

Korolev, V. N., N. Y. Syromyatnikov, and E. M. Tolmachev, "The Structure of Fixed and Fluidized Granular Beds near Immersed Walls," J. Eng. Phys., 21(6), 973 (1971).

Kubie, J., and J. Broughton, "A Model of Heat Transfer in GasFluidized Beds," Int. J. Heat Mass Transf., 18, 289 (1975).

Kuipers, J. A. M., "A Two-Fluid Micro Balance Model of Fluidized Beds," PhD Diss., Twente Univ. of Technology, The Netherlands (1990).

Kuipers, J. A. M., W. Prins, and W. P. M. van Swaaij, "Theoretical and Experimental Bubble Formation at a Single Orifice in a TwoDimensional Gas-Fluidized Bed," Chem. Eng. Sci., 46(11), 2881 (1991).

Kuipers, J. A. M., K. J. van Duin, F. P. H. van Beckum, and W. P. M. van Swaaij, "A Numerical Model of Gas-Fluidized Beds," Chem. Eng. Sci., accepted (1992).

Kuipers, J. A. M., H. Tammes, W. Prins, and W. P. M. van Swaaij, "Experimental and Theoretical Porosity Profiles in a Two-Dimensional Gas-Fluidized Bed with a Central Jet," Powder Technol, accepted (1992).

Mickley, H. S., and D. F. Fairbanks, "Mechanism of Heat Transfer to Fluidized Beds," AIChE J., 1(3), 374 (1955).

Ozkaynak, T. F., and J. C. Chen, "Emulsion Phase Residence Time and Its Use in Heat Transfer Models in Fluidized Beds," AIChE $J ., 26(4), 544$ (1980).

Prins, W., "Fluidized Bed Combustion of a Single Carbon Particle," PhD Diss. Twente Univ. of Technology, The Netherlands (1987).

Rowe, P., "Experimental Properties of Bubbles," Fluidization, J. F. Davidson and D. Harrison, eds., Academic Press, p. 121 (1971).

Schlünder, E. U., "Wärmeübergang an Bewegte Kugelschüttungen bei Kurzfristigem Kontakt," Chemie Ing. Techn., 43, 651 (1971).

Syamlal, M., and D. Gidaspow, "Hydrodynamics of Fluidization: Prediction of Wall to Bed Heat Transfer Coefficients," AIChE J., 31(1), 127 (1985).

Wunder, R., "Wärmeübergang an Vertikalen Wärmetauscherflächen in Gaswirbelschichten,"' PhD Diss., TU München, Germany (1980).

Zehner, P., and E. U. Schlünder, "Wärmeleitfähigkeit von Schüttungen bei Mässigen Temperaturen," Chemie Ing. Techn., 42(14), 933 (1970).

\section{Operators}

$$
\begin{aligned}
\nabla & =\text { gradient } \\
\nabla \cdot & =\text { divergence }
\end{aligned}
$$

